\title{
THE
}

$12-23-2020$

\section{Peer Influence in Initiation to Heroin Use}

\author{
Barbara J. Costello \\ University of Rhode Island, costello@uri.edu
}

Bradley J. Anderson

Michael Stein

Follow this and additional works at: https://digitalcommons.uri.edu/soc_facpubs

The University of Rhode Island Faculty have made this article openly available.

Please let us know how Open Access to this research benefits you.

This is a pre-publication author manuscript of the final, published article.

Terms of Use

This article is made available under the terms and conditions applicable towards Open Access

Policy Articles, as set forth in our Terms of Use.

\section{Citation/Publisher Attribution}

Costello, B. J., Anderson, B. J., \& Stein, M. (2020). Peer Influence in Initiation to Heroin Use. Journal of Drug Issues. https://doi.org/10.1177/0022042620979628

This Article is brought to you for free and open access by the Sociology \& Anthropology at DigitalCommons@URI. It has been accepted for inclusion in Sociology \& Anthropology Faculty Publications by an authorized administrator of DigitalCommons@URI. For more information, please contact digitalcommons-group@uri.edu. 
Peer Influence in Initiation to Heroin Use

Barbara J. Costello $^{\mathrm{a}}$, Bradley J. Anderson ${ }^{\mathrm{b}}$, and Michael Stein ${ }^{\mathrm{c}}$

${ }^{a}$ University of Rhode Island, Department of Sociology and Anthropology, Kingston, RI 02822, USA, Costello@uri.edu, 401-874-2877

${ }^{b}$ Behavioral Medicine Department, Butler Hospital, Providence, RI 02906, USA, Bjanderson@butler.org, 401-486-0703

${ }^{\mathrm{c} B e h a v i o r a l ~ M e d i c i n e ~ D e p a r t m e n t, ~ B u t l e r ~ H o s p i t a l, ~ P r o v i d e n c e, ~ R I ~ 02906, ~ U n i t e d ~ S t a t e s ~}$

Boston University School of Public Health, Department of Health Law, Policy \& Management, Boston, MA 02118, USA, Michael_stein@brown.edu, 617-358-1956 


\section{Peer Influence in Initiation to Heroin Use}

Most people who begin using or misusing opioid drugs acquire these substances from friends and family members. Most misuse of prescription opioids is the result of the use of medications that were not prescribed for those misusing them (Rawson, Maxwell, \& Rutkowski, 2007; Szalavitz, 2016), and approximately two-thirds of those misusing these drugs acquire them in some way from friends or family members (Lankenau et al., 2012; Lipari and Hughes, 2017; Rigg et al., 2019). Those who misuse opioids and other prescription drugs typically have a history of using or abusing other illicit drugs (Mui, Sales, and Murphy, 2014; Satel, 2007), and are likely to be enmeshed in drug using social networks (Carlson et al., 2016; Harocopos, Allen, \& Paone, 2016).

Studies of heroin use show even higher rates of initiation from friends or family members. All of the participants in two small studies of heroin users, one group of American female adolescents (Eaves, 2004) and another study of Indian males (Kermode et al., 2009) reported being initiated to heroin by a friend or family member. A study of young users of heroin in Baltimore found that over $98 \%$ of them first used with friends or family, typically in a small group or party setting (Ghandi, Kavanagh, and Jaffe, 2009). Similar results were obtained from a sample of heroin users in Calcutta, India, with $90 \%$ of first use occurring in a small group of friends (Chowdhury and Sen, 1992). Studies specifically focusing on injecting heroin and other drugs ${ }^{1}$ also find very high rates of initiation by others who inject drugs (Goldsamt et al., 2010; Simpson et al., 2020; Wenger et al., 2016; Werb et al., 2016). One study of persons who inject heroin found only ten percent reporting being initiated by someone other than family or friends or being self-taught how to inject (Day, Ross, Dietze, and Dolan, 2005).

Criminological research has similarly documented that people who use drugs are likely to be enmeshed in social networks of others who use drugs, and this holds for criminal and deviant behavior other than drug use as well. This pattern is one of the best-documented findings in criminology (Costello and Hope, 2016; Shaw and McKay, 1942; Sutherland, 1947; Warr, 2002). In addition, there is strong 
empirical support for versatility in crime and deviant behavior such as drug use (DeLisi, 2003;

Gottfredson and Hirschi, 1990; Mazzerolle and McPhedran, 2018). This refers to the fact that those who engage in deviant behaviors at higher rates tend not to specialize in any form of deviant or criminal behavior, and that offenders tend to engage in a variety of both legal and illegal substance misuse in addition to crime.

This evidence suggests that heroin use and dependence may have the same causes as the use and misuse of other intoxicating substances and criminal behavior more generally. One of these causes is likely contact with friends and family who promote, condone, or simply provide the opportunity for individuals to use drugs. However, the research literature in criminology rarely cites the literature on drug misuse and dependence, much of which has a medical focus. Similarly, the literature focused on drug use and dependence rarely cites the research in criminology that is focused on the peer effect. Neither body of literature has adequately addressed the question of why those who use heroin would initiate others to its use, and conversely, whether and why one might try to prevent initial heroin use in others.

The purpose of the current study is to investigate these issues. Drawing on prior research on motives of both positive and negative peer influence (Costello and Zozula, 2016), and drawing on Gottfredson and Hirschi's (1990) general theory of crime, we hypothesize that those with lower selfcontrol will be more likely to initiate others, and less likely to report trying to prevent others from first use. We also examine the motives for initiating others, and predict that those motives will be more selfinterested than other-directed.

\section{Extent and Motives of Peer Influence}

In the literature on both drug use and crime and deviance more generally, there is ample evidence of homophily - that is, people who engage in crime or drug use are likely to have peers (friends, family, or romantic partners) who engage in the same behaviors (Li et al., 2017; Kandel, 1996). Some of the 
earliest criminological theories were designed in part to explain this pattern (Shaw 1931; Shaw and McKay 1942; Sutherland 1947). Despite the existence of clear evidence of homophily, however, there has been a great deal of debate over the reasons for this pattern. Historically, differential association and social learning theories claimed to explain the correlation, with the argument that deviant peers cause deviant behavior by teaching norms conducive to the behavior (Burgess and Akers, 1966; Sutherland, 1947). Control theorists generally argued that the correlation could be explained by self-selection (Hirschi, 1969), or that the magnitude of the relationship was artificially inflated by asking respondents to report on the behavior of their peers (Gottfredson and Hirschi, 1990). The self-selection versus socialization debate has continued for many years, with much research suggesting that both play a role (Kandel, 1978). Starting around the mid-1990's, researchers began exploring alternative explanations for the peer effect, such as friends simply providing the opportunity for deviance (Desmond, Bruce, and Stacer 2012; Hoeben and Weerman, 2016; Osgood et al 1996; Osgood and Anderson 2004). Scholars have noted the wide range of possible explanations for the peer effect, and the need for further research into alternatives to selection and socialization (Costello and Hope, 2016; Warr, 2002).

Much research specific to drug misuse and dependence is conducted by medical researchers and psychologists, and tends not to draw on criminological theory. However, this body of literature has clearly noted a peer effect, and researchers have proposed a number of explanations for the correlation between drug use and having friends who also use drugs. For example, the transition from non-injection heroin use to injection use has been found to be related to social network characteristics such as communication with those promoting injection, and the perception that members of the social network condone heroin injection (Neaigus et al., 2006). Women's initiation to methamphetamine use involves a combination of social network influence and individual desire to try the drug, often combined with a history of using other drugs (Carbone-Lopez, Owens, \& Miller, 2012). A qualitative study of injection heroin users in rural Ohio found that initiation occurred in social groups in which the use of drugs was normalized, and that friends can promote injection by touting the increased euphoria attained through injection over 
sniffing heroin (Draus and Carlson, 2006). A desire for belonging to a group was offered as a reason for initiation to heroin or cocaine by $40 \%$ of a sample of young drug users in Amsterdam (Witteveen et al., 2007). Eaves (2004) suggests that peers who use heroin reduce the stigma associated with heroin use, and also provide the knowledge of how to inject.

One question that has been largely overlooked in both criminological research and research focused on drug use, however, is why individuals try to influence their peers either toward or away from drug use/injection and deviant behavior. A recent review of the literature on peer influence among adolescents notes that motives for peer influence are virtually ignored in the literature, and understanding these motives could be central to understanding the process of peer influence (Brown et al., 2008). Prior research has suggested that motives for influencing peers toward deviance might be related to the desire to enhance one's status in a group or to enforce relationship norms (Brown et al., 2008). One study designed in part to address motives toward initiating others to heroin injection found that $37 \%$ of participants had taught someone how to inject, but the only significant predictor of teaching others to inject was length of time the instructor had been injecting (Day et al., 2005). There were no significant differences in the likelihood of initiating others by sex, ethnicity, or age (Day et al., 2005). A study of injection initiation assistance in Mexico found that the use of non-injection drugs was associated with initiating others to injection drug use, likely due to the increased opportunity for initiating others provided by using non-injection drugs in group settings (Hamida et al, 2018). Bryant and Treloar (2008) found initiators to injection were more likely to be male, to have injected for a longer period of time, and to be more likely to pass on information about safe injection practices to their initiates. Other studies have found additional correlates of initiating others, including being male, unemployed, and having injection drug-using friends (Kermode et al., 2007), and that being "on the dole," dealing drugs, and injecting more than one drug were significantly associated with initiating multiple others (Crofts et al., 1996).

One study of deviant behavior among university students focused specifically on motives for both positive and negative peer influence (Costello and Zozula, 2016). Drawing on prior research suggesting 
that peer influence toward deviance is self-interested (Costello and Hope, 2016), and on Gottfredson and Hirschi's (1990) argument that deviant behavior is caused by low self-control, Costello and Zozula argued that motives for pro-deviant peer influence would be more likely to be self-interested than motives for anti-deviant or prosocial peer influence.

Gottfredson and Hirschi's self-control theory holds that crime and analogous behaviors such as substance use provide quick and easy gratification of desires, require little skill to complete, are rarely planned in advance, and often result in negative outcomes for both victims of crime as well as those who engage in it. They argue, then, that people who commit crime tend to be impulsive, to pursue short-term pleasures that often incur long-term costs, and that they have difficulty pursuing long-term goals that require the development of skills (Gottfredson and Hirschi, 1990). Offenders tend to be self-interested, willing to exploit others for their own gains, and likely to have unstable employment histories and social relationships. Although they may be gregarious and sociable, offenders tend not to put others' needs before their own. As Gottfredson and Hirschi put it, criminal behavior is "antigroup" behavior, and often involves victimizing one's own friends or associates (1990:156). Self-control theory is very wellsupported empirically across a variety of different samples and outcome variables, including health risk behaviors (Pratt and Cullen, 2000; Vazsonyi, Mikuška, \& Kelley, 2017).

Costello and Zozula (2016) view peer influence toward deviance or drug use as analogous to criminal behavior, and thus proposed that influencing friends toward deviance would be more likely to be rooted in the self-interested motives characteristic of those with low self-control. In contrast, they held that peer influence away from deviance or toward prosocial, productive behavior would be more likely to be motivated by concern for the other. Their findings supported the idea that peer influence toward deviance, most commonly drinking alcohol, was likely to have selfish motives. Motives classified as selfish included respondents wanting someone to be deviant with them because it would assuage their own guilt over the behavior or because they wanted to engage in an activity but wanted someone else to do it with them to enhance their own enjoyment. In other cases, respondents encouraged deviance or 
substance use for more altruistic reasons, such as the belief that using marijuana would help someone relax and have fun.

Costello and Zozula (2016) also found both selfish and altruistic motives for positive influence. Attempts at preventing substance use to protect a friend's health or safety, as in preventing someone from driving under the influence, were common. There were some examples of selfish motives for positive peer influence as well, although these were less common. Overall, Costello and Zozula (2016) found that $53 \%$ of the reported motives for deviant peer influence were selfish, $36 \%$ were altruistic, and $10 \%$ could not be classified in either direction. In contrast, only $12 \%$ of reported motives for prosocial or anti-deviant peer influence were selfish, $83 \%$ were altruistic, and $6 \%$ could not be classified. Costello and Zozula (2016) argued that these results were supportive of self-control theory's view of offenders as selfinterested, and suggested that efforts to reduce deviant behavior and substance use might focus on educating youths about the selfish motives behind much peer pressure toward deviance.

Few studies of heroin initiation or injection initiation provide insight into the motives behind initiating others to heroin use or injection (Simpson et al., 2020). A number of studies have asked respondents how they were initiated, and peer influence is often mentioned as a factor in first use of heroin (Daniulaityte, Carlson, and Kenne, 2006; Eaves, 2004; Goldsamt et al., 2010; Kermode et al., 2007; Kermode et al., 2009; Lankenau et al., 2010; Witteveen et al., 2007). However, little is known about the exact nature of the peer influence, or what motivated the person doing the influencing. There is evidence from two studies that heroin users or dealers might trick people into using for the first time by mispresenting heroin as some other drug. Furst et al. (2004) had several respondents report being tricked into using heroin for the first time by someone telling them it was cocaine. One of these respondents went on to trick fourteen other people into using for the first time, several of whom then started buying heroin from him. The authors suggest that getting new customers or new people to sell drugs might have been a motive for tricking others, or that creating new heroin users might be a way to reduce the stigma of using (Furst et al., 2004). Another small study of people who use heroin found tricking to be the most 
commonly reported reason for initiation, with six of ten respondents reporting being tricked the first time they used (Best, Manning, and Strang, 2007). A third study provides indirect evidence that tricking might have been a factor in first use of heroin or cocaine, with $40 \%$ of the sample reporting "misinformation or accident" as a reason for first use (Witteveen et al., 2007: 45). Qualitative studies focused specifically on injection drug use reveal that there are norms against initiating others (Wenger et al., 2016), but that these norms are frequently violated, in some cases due to potential economic benefits of injecting someone (Small et al., 2009). This finding is consistent with the idea that those with low self-control, who are more self-interested, are more likely to initiate others.

On the other hand, there is also evidence that initiation to injection drug use occurs when current drug users express a desire to inject, and approach persons who inject for help in injecting. Some research finds that "curiosity" is a common reason for first injection (Goldsamt et al., 2010; Lankenau et al., 2010), and there is evidence that users persist in trying to convince "trainers" to inject them even when they initially refused (Goldsamt et al., 2010; Simpson et al., 2020; Wenger et al., 2016). Some respondents report that their trainers only relented because the new initiate threatened to go to a stranger to inject, and that the trainer was trying to protect them (Goldsamt et al., 2010). In these cases, the trainer appears to have been acting altruistically, in contrast to the image portrayed by those reporting being tricked into using for the first time. Wenger et al. (2016) note several cases in which trainers inject others to prevent them from injuring themselves by self-injecting incorrectly, despite having serious moral reservations about doing so. Similarly, in-depth interviews with a small sample of injectors in Vancouver revealed instances of initiates seeking out more experienced injectors, and in some cases working to convince them to help them inject or to inject them (Small et al., 2009). Werb et al. (2018) note that people with a desire to initiate injection drug use can be very persistent in their requests to others for assistance. It is possible that some of the differences reported in research on the pathways to heroin use are associated with the distinction between first use of heroin by any method of administration and injection, as those who inject typically have prior experience with heroin use by other methods. 
The purpose of the current research is to investigate the reasons for initiating others to heroin use, and to investigate the extent to which users report trying to prevent others from first use of heroin. Assuming that most persons who use heroin understand the potential negative effects of heroin dependency, why would they encourage or enable others to start using? Are their motives selfish, as suggested by self-control theory and prior research (Costello and Zozula, 2018; Gottfredson and Hirschi, 1990), or are they likely to be focusing on the potential positive experience for the new user, such as the psychoactive effects or pain reduction? On the other hand, are current users likely to try to help others avoid using heroin and potentially becoming addicted? Prior research on positive peer influence among college students suggests that positive influence may be even more common than negative peer influence (Costello and Hope, 2016). The extent to which this pattern holds in a more deviant population is also a focus of this investigation.

Following the logic of self-control theory, we hypothesize that there is a negative association between self-control and initiating others to heroin use, and a positive correlation between self-control and trying to prevent peer initiation. We also investigate the motives reported by those who have initiated others, with an eye toward distinguishing between selfish motivations and more benign or altruistic motives. Finally, we examine respondents' reports of their own reasons for initiating opioid use to gain insight into peer influence processes that led to their own initiation.

\section{Methods}

Sample

Participants were recruited from the Stanley Street Treatment and Resources, Inc. (SSTAR) in Fall River, MA between September 2016 and April 2017. Research assistants approached persons entering a short-term inpatient opioid managed withdrawal program after patients' initial dose of methadone, but within 24 hours of admission to the SSTAR facility. After verbal assent, data were collected by research assistants who were not involved in the clinical treatment of participants. 
During the recruitment period, 417 persons were approached for screening. Persons approached were opioid users, 18 years of age or older, English-speaking, and able to provide informed consent as approved by the Butler Hospital Institutional Review Board. Thirty refused study participation or were discharged before staff could interview them. The remaining 387 persons completed a 15 -minute, nonincentivized, face-to-face interview administered by non-treating research staff. This analysis is limited to the 370 persons who reported heroin use in the past 30 days.

\section{Measures}

The measures used in the current study include demographic characteristics, questions about whether the individual had initiated others to heroin use, and whether they had tried to prevent others from initiating heroin use (Table 1). A set of questions measured motives for initiating others, and reasons why the individual him- or herself initiated heroin use, that were derived from the literature (see Tables 3 and 4). The Grasmick et al. (1993) self-control index was used to measure self-control (see Appendix A.)

\section{Analytical Methods}

We present descriptive statistics to summarize the characteristics of the sample. We used logistic regression to test the hypotheses that, after controlling for background characteristics (sex, race, ethnicity, years of heroin use, and primary drug used), self-control would be inversely associated with the likelihood of initiating others to heroin, and positively associated with trying to prevent others from using heroin for the first time. Descriptive statistics for respondents' stated reasons for initiating others, and their own reasons for initiating, are also presented, along with a classification of those reasons as selfinterested or other-directed.

\section{Results}


Participants averaged 33.5 years old, $25.1 \%$ were female, $10.5 \%$ were Latino/a, $83.2 \%$ were White, $2.7 \%$ were Black, and $14.1 \%$ were identified as other or mixed race (Table 1); mean years of heroin use was 9.34. Most (87.8\%) said heroin was the opioid from which they were currently seeking treatment. The mean score on the 24-item self-control scale was $69.9( \pm 10.0)$. Sixty-five $(17.6 \%)$ participants said they had previously introduced persons to heroin; 34 said they had done so only once, 15 said they had introduced others to heroin 2-3 times, and 16 said they had done so 4 or more times (not shown in table). This was dichotomized in subsequent analyses.

Trying to prevent someone from initiating heroin use was more common than initiating someone to heroin, with about $72 \%$ of the sample saying that they had tried to prevent others from initiating heroin use. About $8 \%$ of the sample reported preventing first use only once, with about $32 \%$ reporting 2 or 3 times, and about $32 \%$ reporting 4 or more occasions (not shown in table). With regard to the success of the most recent attempt to prevent first use, $53 \%$ reporting the attempt was successful ${ }^{2}$, with $45 \%$ saying it was not. About $12 \%$ of the sample, or 45 respondents, report both trying to prevent others' initiation and initiating someone to heroin use.

A rough estimate of the incidence of initiating others in our sample is 2.4 initiates per respondent, if we assume " 4 or more" is equal to 4 and about half of those answering " $2-3$ " times initiated two and half initiated three other people. Introducing others to heroin was dichotomized in subsequent analyses.

Participants were asked about the most recent time they had introduced others to heroin. Consistent with what we would expect based on prior research, most (about 97\%) reported that they knew the person they initiated, most commonly a friend. Fifty-five (80.9\%) said they had known that person for a year or more, and only two (2.9\%) said they had known the person for less than a week.

Consistent with our first hypothesis, self-control was negatively related to the likelihood of initiating others to heroin, controlling for demographic characteristics, years of heroin use, and detox drug $(\mathrm{z}=-3.23, \mathrm{p}=.001$, see Table 2). Each additional 1-point increase in self-control was associated with an estimated .95 factor reduction in the expected odds of initiating others. ${ }^{3}$ The likelihood of initiating others 
was not associated significantly with other variables in the model.

On the other hand, contrary to our hypothesis, self-control was not associated significantly with the likelihood of trying to prevent others from initiating heroin use ( $O R=0.98, p=.132)$ (Table 2). The expected odds of trying to prevent others from heroin initiation were about $57 \%$ lower for males than females $(\mathrm{OR}=0.57)$ though this association was only marginally significant statistically $(\mathrm{p}=.055)$. Persons identifying as two or more races or other racial identifications were significantly more likely than Whites to report they had tried to prevent others from initiating heroin use $(\mathrm{OR}=2.84, \mathrm{p}=.024)$. Trying to prevent others from initiating heroin use was not associated significantly with any of the other variables included the model.

Participants were also asked about the reasons they had most recently introduced someone to heroin. They were presented with a list of reasons that were not mutually exclusive (Table 3). We categorized each reason according to how self-focused or other-focused the reason was, with "They asked me for it," "I thought they would enjoy it," and "They were withdrawing ..." being more altruistic or other-focused and the remaining items being more self-interested. The most frequently endorsed reasons for introducing others to heroin were that they asked for the drug, they thought the other person would enjoy heroin, and the person was withdrawing. Sixty-four (94.1\%) endorsed at least one of the more altruistic reasons. Some of the more commonly endorsed self-interested motives were that the respondent wanted someone to do heroin with, they wanted to do heroin with that person, and they were dealing and trying to get new business; $24(35.3 \%)$ endorsed at least one of the items classified as more selfinterested. About 32.3\% endorsed at least one altruistic reason and at least one self-interested reason. Estimating whether those with lower self-control were more likely to endorse self-interested reasons for initiation was complicated by the fact that the stated motives were not mutually exclusive. As noted above, $94 \%$ of the sample endorsed at least one of the altruistic reasons, and the altruistic reasons for initiation were clearly more common than the self-interested ones. Only one person in the sample endorsed a self-interested reason and none of the altruistic reasons. However, we did analyze the 
correlations between self-control and the number of altruistic and self-interested motives endorsed, neither of which was statistically significant. Forty-two people endorsed one or more altruistic reason and no self-interested ones, and there was no significant relationship between self-control and a dichotomous “altruistic motive only" vs. "other" variable.

Respondents reasons for initiating heroin use are presented in Table 4. Respondents could endorse multiple items. We categorized three items as indicating a selfish motive on the part of supplier"Someone pressured me into using it," "Someone tricked me into using it," and "I thought it would make someone happy if I used it with them." Two responses were seen as possibly indicating unselfish or even altruistic motives on the part of the supplier - "I was withdrawing . . . and someone else suggested that heroin would help," and "Someone offered and I accepted." The most commonly endorsed items were those that were neutral in terms of the motives of the supplier - "It was cheaper" than pain pills was the most commonly endorsed item, followed very closely by "I just wanted to try it." Two of the items that were classified as more altruistically motivated, someone offered (about 53\%), and someone suggested heroin to relieve withdrawal symptoms (40\%) were also commonly endorsed. The items indicating selfish motives on the part of the supplier were not endorsed very frequently (being tricked, pressured, or to make someone else happy.) Thus, the evidence in Table 4 does not support our expectations regarding the motives of those introducing others to heroin use for the first time, and the results show that neutral or altruistic imputed motives are much more common.

\section{Discussion}

Our results supported the hypothesis that those with lower levels of self-control are more likely to initiate others to heroin use, controlling for background characteristics such as years using heroin, sex, age, and race. Given Gottfredson and Hirschi's (1990) conceptualization of those with low self-control as being impulsive, pleasure-seeking, and self-interested, this finding lends credibility to the idea that those who initiate others to heroin use do so for self-interested motives. In this way, then, initiating others can 
be viewed as analogous to criminal behavior, and likely to have similar predictors. However, the direct reports of the motives of those who have initiated others do not support this idea, as initiators are more likely to report other-directed or altruistic motives for initiating others. The most common reason by far for providing heroin to others was that the person asked for it, followed by the idea that the person would enjoy it. Similarly, the most common reasons for our respondents' first use of heroin do not suggest selfinterest on the part of the person providing the drug for them. The most common reasons given for initiation of heroin use are more indicative of a desire to try a new drug because of cost or because of curiosity.

It is also possible that those with lower self-control are more likely to initiate others not out of pure self-interest, but because they find it more difficult to resist repeated and persistent requests for heroin. Simpson et al. (2020) found that $41 \%$ of their sample reported "pestering" as a reason for initiating someone else to injection drug use in their sample. Wenger et al. (2016) describe one respondent's experience with a roommate who asked her for about a year to give him "speedballs," or a mixture of heroin and cocaine. She finally relented, in part because she needed money to support her own drug habit (Wenger et al., 2016). In this case, a combination of pressure from the roommate and the need for money seem to have worked together to lead to this case of injection initiation.

The phenomenon of "pestering" raises an interesting distinction between the literature on heroin initiation and group delinquency. Warr (1996) found that delinquent groups generally have an "instigator" and one or more "joiners," with instigators being the group member who suggested the offense to the group. It seems that a great deal of heroin initiation and injection drug initiation is actually suggested by the person who has not previously used heroin or injection drugs, and the older, more experienced "initiators" in Warr's study are perhaps more appropriately thought of as the "joiners" who agree to provide heroin or injection assistance. A key issue in comparing these two types of groups, however, is in their prior experience with the behavior in common, as well as the issue of drug dependency. The vast majority of those initiating heroin use have an extensive background of using drugs, and in at least some 
cases are dependent on them. The youths in Warr's study were aged 13-16 at the time of the study, and most of the delinquent behaviors measured were nonserious offenses. These contrasts point out the need to consider processes involved not just in heroin or injection drug use initiation, but also the group processes that led to initial drug use. Initial drug use may be more likely to follow the patterns uncovered in Warr's study.

Our results did not support the hypothesis that those with higher self-control would be more likely to report preventing others from initiating. It was interesting, however, that such a large percentage of the sample reported trying to prevent initiation, with a majority of the sample reporting attempting this at least once, and about $64 \%$ of the sample reporting doing this more than once. Further, $53 \%$ of those reporting prevention attempts reported that their most recent attempt was successful. Although we have no way of knowing whether the people who did not initiate heroin use as a result of our respondents' actions will permanently avoid using heroin, it is possible that the respondents in this sample have prevented hundreds of people from initiating heroin use. In addition, although there is little research on the issue of positive peer influence among opioid users (Barnes et al., 2018), there is some evidence that pressure against injection drug use can cause youths to stop injecting (Small et al., 2009). One respondent in a study of Vancouver youth stated, regarding his friends, “. . . they're like the slap in the head everybody kind of needs." Another participant in that study said, "I stopped doing it with needles as well because other people that are close to me are shaking their heads at me because I use needles, right? So then I was like "whoa, I actually use needles"” (Small et al., 2009).

The results of these studies and the current research strongly suggest that future research systematically address peers as a source of influence away from initiating heroin use and/or injecting drugs. There have been interventions designed to discourage injection drug users from initiating other's injection drug use, and some of these have shown positive results. For example, the "Break the Cycle" and "Change the Cycle" interventions were designed to educate injection drug users on the consequences of initiating others, and to provide strategies to resist others' requests for assistance with injection 
initiation (Hunt et al., 1998; Strike et al., 2014; Werb et al., 2018; Werb et al., 2013). Evaluations of these programs found significantly fewer initiation incidents and positive talk about injection in front of noninjection drug users following participation, and there are similar studies currently ongoing (Werb et al, 2018). There is also a need for further research on the correlates of and reasons for opioid drug users preventing others' initiation to heroin use who may not have participated in such programs, and who may not be injection drug users themselves. The majority of our sample reports such behavior, and aside from a near-significant gender effect, it is not clear why some users are more likely to try to deter others from initiating. It would be beneficial for future research to explore this issue with qualitative research designs, which tend to be underutilized in criminological research (Copes, 2014).

It is important to note the overall evidence from this and other research on the effect of simple opportunity on drug use or other deviant behaviors. It is clear that most people who initiate heroin use, via injection or by other methods, do so at least in part because they are provided the opportunity by exposure to other users. There is ample evidence that witnessing others injecting drugs increases the desire to inject, and of course provides a source of information and assistance with injection. Similarly, there is a great deal of evidence that heroin users typically have a history of using other illicit drugs such as prescription opioids (Gaines et al., 2020; Guarino et al., 2018), as well as other common correlates of crime and deviance such as abusing alcohol and poor school performance (Meich et al., 2015). Although using legitimately prescribed opioids can lead to addiction, only a small percentage of those who are prescribed opioid medications for pain become addicted, and only about $4 \%$ of those who are addicted to opioids will transition to heroin (Volkow and McLellan, 2016). That may very well be because few people are enmeshed in social networks that provide the opportunity to transition to heroin use.

Costello and Hope's (2016) study of peer influence among college students revealed the counterintuitive pattern that the highest frequency of positive peer influence attempts occurred among those who report the highest level of deviant behaviors. They attribute this to opportunity - because deviant behavior is often carried out in the company of peers, more deviant individuals have the greatest opportunity to 
intervene in their friends' potential deviance. Friends might not let friends drive drunk, but friends who don't drink are unlikely to be in a position to prevent an intoxicated friend from driving. Given the clear evidence that heroin initiation is usually carried out with friends, family, or acquaintances, there is a need for more research on how to facilitate positive peer influence among those who are most likely to have the opportunity to prevent the use of heroin - those who themselves use heroin and other illicit substances.

Finally, it is important to note the limitations of the current study. As is the case with most studies of those who use opioid drugs, our sample is from a single site, and although large relative to many studies of persons who use heroin, it cannot be assumed to be representative. We study influence toward first use of heroin by any method of administration, and because most first-time users do not inject, our results cannot be assumed to apply to injection initiation.

Social desirability bias in responses might account for our sample being on the lower end of published estimates of the prevalence and incidence of initiating others to opioid drug use. Compared to other studies of the prevalence and incidence of initiating others, our sample would fall on the lower end. Werb et al. (2018) report a range of prevalence in the literature between $17 \%$ and $47 \%$, and a range of number of initiates between 2 and 15.5, compared to our prevalence of $17.6 \%$ and an estimated 2.4 initiates per respondent. Social desirability might also explain the high frequency of respondents' reports of preventing others from initiating. However, in a study focusing on those who had been asked to initiate injection drug use, Bluthenthal et al. (2014) found similarly high rates of refusing to initiate others, with $73 \%$ of their sample reporting refusal at least once compared to about $72 \%$ in the current study. Our study did not focus on the role of drug markets or wider social networks in driving heroin initiation, nor the consumption of other legal substances (cigarettes, alcohol) or illegal drugs prior to initiating heroin use. In addition, we do not ask the reasons for respondents initiating forms of opioid use other than heroin, which in the trajectory of substance use, often precedes heroin use (Gaines et al., 2020; Guarino et al., 2018). Finally, beyond the idea of curiosity ("I just wanted to try it"), which was commonly reported here, we did not explore the idea of pleasure-seeking as a reason for heroin initiation that might be quite 
powerful and would suggest greater agency among persons who often already use opioids.

Another limitation of this research pertains to the timing of the measures of the independent and dependent variables. Self-control is measured at the time of entry into a treatment program, and the measures of the dependent variables are all retrospective measures of lifetime prevalence. There is substantial evidence for the stability of self-control over the life course (Beaver et al., 2008; Gottfredson and Hirschi, 1990; Hay and Forrest, 2006). However, much of this research has been conducted on youths and adolescents, and the generalizability of those findings to this population cannot be assumed. The respondents were voluntarily seeking treatment for opioid use, an act that requires self-control, so estimates of their self-control might be biased upward, or they may be atypical of opioid users in general. In addition, theoretical predictors other than self-control were not included in the study.

Another limitation of our study is that we did not ask respondents questions about their motives for preventing others' initiation of heroin use. A recent qualitative study specifically focused on injection initiation did ask about respondents' motives for not initiating others (Barnes et al., 2018). That study revealed three different types of motivations: the altruistic desire to avoid harm, the perception of lack of their own skill in injecting others, and an absolute moral refusal to ever initiate anyone to injection. Arguably, all of these motives can be classified as altruistic to some extent, which is consistent with Costello and Zozula's (2018) findings regarding motives for positive peer influence. It will be important for future research to further investigate motives for initiating others to drug use, to refuse to initiate others, and to actively try to prevent others' first use of heroin and other harmful substances. These lines of inquiry may lead to prevention strategies that could help people avoid becoming drug dependent. 


\section{NOTES}

${ }^{1}$ Our measures in this study focus specifically on heroin use by any method of administration.

One of the primary goals of the study is to understand more about motives for peer influence both toward and away from harmful behaviors. Although there are separate bodies of research focusing on heroin initiation, heroin injection initiation, and injection of other drugs, we review all of these bodies of literature as they relate to the issue of peer influence and motives for peer influence. We hypothesize that peer influence toward initiation is likely to be motivated by self-interested concerns, following the logic of self-control theory. Because the literature on injection initiation documents altruistic motives for initiation, contrary to our hypothesis, we thought it was important to review this literature to give a more complete picture of what is known about peer influence processes. That having been said, we do not argue that our results are directly applicable to injection initiation. The respondents in our study are reporting on first use of heroin, which is very unlikely to be via injection.

${ }^{2}$ We did not include measures of whether or not attempts at initiating others were successful. This might be interesting to study from the perspective of resistance to peer pressure or opportunities for deviance.

${ }^{3}$ Our primary focus in this research was on self-control as a unified theoretical construct, but we also estimated six additional logistic regression models using Grasmick et al.'s (1993) measures of the six dimensions of self-control. Adjusting for sex, ethnicity, race, years of heroin use, and history of prior managed heroin withdrawal, the likelihood of introducing others to heroin was associated significantly and in the expected direction with impulsivity $(\mathrm{OR}=0.61,95 \% \mathrm{CI} 0.39 ; 0.96, \mathrm{z}=-2.12, \mathrm{p}=.034)$, risk taking $(\mathrm{OR}=0.60,95 \% \mathrm{CI} 0.41 ; 0.88, \mathrm{z}--2.63, \mathrm{p}=.008)$, self-centeredness $(\mathrm{OR}=0.49,95 \% \mathrm{CI} 0.32$; $0.75, \mathrm{z}=-3.23, \mathrm{p}=.001)$, and temper $(\mathrm{OR}=0.56,95 \% \mathrm{CI} 0.38 ; 0.82, \mathrm{z}=-2.95, \mathrm{p}=.003)$, but not with a preference for simple tasks or preference for physical rather than cognitive tasks. Trying to prevent others from using heroin was not associated significantly with any of the 6 sub-scales. 


\section{REFERENCES}

Barnes, D. M., Des Jarlais, D. C., Wolff, M., Feelemyer, J., \& Tross, S. (2018). A qualitative study of persons who inject drugs but who have never helped others with first injections: how their views on helping contrast with the views of persons who have helped with first injections, and implications for interventions. Harm Reduction Journal, 15(1), 43.

Beaver, K. M., Wright, J. P., DeLisi, M., \& Vaughn, M. G. (2008). Genetic influences on the stability of low self-control: Results from a longitudinal sample of twins. Journal of Criminal Justice, 36(6), 478485.

Best, D., Manning, V., \& Strang, J. (2007). Retrospective recall of heroin initiation and the impact on peer networks. Addiction Research \& Theory, 15(4), 397-410.

Bluthenthal, R. N., Wenger, L., Chu, D., Quinn, B., Thing, J., \& Kral, A. H. (2014). Factors associated with initiating someone into illicit drug injection. Drug and alcohol dependence, 144, 186-192.

Brown, B. B., Bakken, J. P., Ameringer, S. W., \& Mahon, S. D. (2008). A comprehensive conceptualization of the peer influence process in adolescence. In M.J. Prinstein and K.A. Dodge (Eds.), Understanding peer influence in children and adolescents, (17-44). New York: Guilford Press.

Burgess, R. L., \& Akers, R. L. (1966). A differential association-reinforcement theory of criminal behavior. Social Problems, 14(2), 128-147.

Carbone-Lopez, K., Owens, J. G., \& Miller, J. (2012). Women's “storylines” of methamphetamine initiation in the Midwest. Journal of Drug Issues, 42(3), 226-246.

Carlson, R. G., Nahhas, R. W., Martins, S. S., \& Daniulaityte, R. (2016). Predictors of transition to heroin use among initially non-opioid dependent illicit pharmaceutical opioid users: A natural history study. Drug and alcohol dependence, 160, 127-134.

Chowdhury, A. N., \& Sen, P. (1992). Initiation of heroin abuse: The role of peers. Indian Journal of Psychiatry, 34(1), 34.

Colon-Berezin, C., Nolan, M. L., Blachman-Forshay, J., \& Paone, D. (2019). Overdose deaths involving fentanyl and fentanyl analogs-New York City, 2000-2017. Morbidity and Mortality Weekly Report, 68(2), 37.

Copes, H. (2014). Introduction: Advancing qualitative methods in criminal justice and criminology. In H. Copes (Ed.), Advancing qualitative methods in criminology and criminal justice, pp. 1-3. Routledge.

Costello, B. J., \& Hope, T. L. (2016). Peer pressure, peer prevention: The role of friends in crime and conformity. Routledge.

Costello, B. J., \& Zozula, C. (2018). Peer influence: Mechanisms and motivations. Deviant Behavior, 39(1), 94-110. 
Crofts, N., Louie, R., Rosenthal, D., \& Jolley, D. (1996). The first hit: circumstances surrounding initiation into injecting. Addiction, 91(8), 1187-1196.

Daniulaityte, R., Carlson, R. G., \& Kenne, D. R. (2006). Initiation to pharmaceutical opioids and patterns of misuse: Preliminary qualitative findings obtained by the Ohio Substance Abuse Monitoring Network. Journal of Drug Issues, 36(4), 787-808.

Delisi, M. (2003). The imprisoned nonviolent drug offender: Specialized martyr or versatile career criminal? American Journal of Criminal Justice, 27(2), 167-182.

Desmond, S. A., Bruce, A. S., \& Stacer, M. J. (2012). Self-control, opportunity, and substance use. Deviant Behavior, 33(6), 425-447.

Draus, P. J., \& Carlson, R. G. (2006). Needles in the Haystacks: The Social Context of Initiation to Heroin Injection in Rural Ohio. Substance Use \& Misuse, 41(8), 1111-1124. doi:10.1080/10826080500411577

Day, C. A., Ross, J., Dietze, P., \& Dolan, K. (2005). Initiation to heroin injecting among heroin users in Sydney, Australia: cross sectional survey. Harm Reduction Journal, 2(1), 2.

Eaves, C. S. (2004). Heroin use among female adolescents: The role of partner influence in path of initiation and route of administration. The American Journal of Drug and Alcohol Abuse, 30(1), 21-38.

Furst, R. T., Herrmann, C., Galea, J., \& Hunt, K. (2004). Heroin diffusion in the mid-Hudson region of New York State. Addiction, 99(4), 431-441.

Gaines, T. L., Wagner, K. D., Mittal, M. L., Bowles, J. M., Copulsky, E., Faul, M., Harding, R. W., \& Davidson, P. J. (2020). Transitioning from pharmaceutical opioids: A discrete-time survival analysis of heroin initiation in suburban/exurban communities. Drug and Alcohol Dependence, 108084.

Gandhi, D. H., Jaffe, J. H., McNary, S., Kavanagh, G. J., Hayes, M., \& Currens, M. (2003). Short-term outcomes after brief ambulatory opioid detoxification with buprenorphine in young heroin users.

Addiction, 98(4), 453-462.

Goldsamt, L.A., Harocopos, A., Kobrak, P., Jost, J.J., and Clatts, M.C. (2010). J Community Health 35(3): 258-267. https://doi.org/10.1007/s10900-010-9231-z

Gottfredson, M. R., \& Hirschi, T. (1990). A general theory of crime. Stanford University Press.

Grasmick, H. G., Tittle, C. R., Bursik Jr, R. J., \& Arneklev, B. J. (1993). Testing the core empirical implications of Gottfredson and Hirschi's general theory of crime. Journal of research in crime and delinquency, 30(1), 5-29.

Guarino, H., Mateu-Gelabert, P., Teubl, J., \& Goodbody, E. (2018). Young adults' opioid use trajectories: From nonmedical prescription opioid use to heroin, drug injection, drug treatment and overdose.

Addictive behaviors, 86, 118-123.

Harocopos, A., Allen, B., \& Paone, D. (2016). Circumstances and contexts of heroin initiation following non-medical opioid analgesic use in New York City. International Journal of Drug Policy, 28, 106-112. 
Harocopos, A., Goldsamt, L.A., Kobrak, P., Jost, John J., Clattset, M.C. (2009). New injectors and the social context of injection initiation. International Journal of Drug Policy, 20(4), 317 - 323.

Hay, C., \& Forrest, W. (2006). The development of self-control: Examining self-control theory's stability thesis. Criminology, 44(4), 739-774.

Hoeben, E. M., \& Weerman, F. M. (2016). Why is involvement in unstructured socializing related to adolescent delinquency?. Criminology, 54(2), 242-281.

Hunt, N., Stillwell, G., Taylor, C., \& Griffiths, P. (1998). Evaluation of a brief intervention to prevent initiation into injecting. Drugs: Education, prevention and policy, 5(2), 185-194.

Lankenau, S. E., Teti, M., Silva, K., Bloom, J. J., Harocopos, A., \& Treese, M. (2012). Initiation into prescription opioid misuse amongst young injection drug users. International Journal of Drug Policy, 23(1), 37-44.

Lankenau, S. E., Wagner, K. D., Bloom, J. J., Sanders, B., Hathazi, D., \& Shin, C. (2010). The First Injection Event: Differences among Heroin, Methamphetamine, Cocaine, and Ketamine Initiates. Journal of Drug Issues, 40(2), 241-262.

Li, Spencer D., Zhang, X., Tang, W., \& Xia, Y. (2017). Predictors and implications of synthetic drug use among adolescents in the gambling capital of China. Sage open 7.4: 2158244017733031.

Lipari, Rachel N. \& Hughes, A. (2017). How people obtain the prescription pain relievers they misuse. https://www.samhsa.gov/data/sites/default/files/report_2686/ShortReport-2686.html

Kandel, D. B. (1996). The parental and peer contexts of adolescent deviance: An algebra of interpersonal influences. Journal of Drug Issues 26, 2: 289-315.

Kandel, D. B. (1978). Homophily, selection, and socialization in adolescent friendships. American Journal of Sociology, 84(2), 427-436.

Kermode, M., Longleng, V., Singh, B. C., Hocking, J., Langkham, B., \& Crofts, N. (2007). My first time: initiation into injecting drug use in Manipur and Nagaland, north-east India. Harm Reduction Journal, $4(1), 19$.

Kermode, M., Longleng, V., Singh, B. C., Bowen, K., \& Rintoul, A. (2009). Killing time with enjoyment: a qualitative study of initiation into injecting drug use in north-east India. Substance Use \& Misuse, 44(8), 1070-1089.

Mazerolle, P., \& McPhedran, S. (2018). Specialization and versatility in offending. The Oxford Handbook of Developmental and Life-Course Criminology, 49-69.

Miech, R., Johnston, L., O’Malley, P. M., Keyes, K. M., \& Heard, K. (2015). Prescription opioids in adolescence and future opioid misuse. Pediatrics, peds-2015.

Mui, H. Z., Sales, P., \& Murphy, S. (2014). Everybody's doing it: Initiation to prescription drug misuse. 
Journal of Drug Issues, 44(3), 236-253.

Neaigus, A., Gyarmathy, V. A., Miller, M., Frajzyngier, V. M., Friedman, S. R., \& Des Jarlais, D. C. (2006). Transitions to injecting drug use among noninjecting heroin users: social network influence and individual susceptibility. JAIDS Journal of Acquired Immune Deficiency Syndromes, 41(4), 493-503.

Osgood, D. W., \& Anderson, A. L. (2004). Unstructured socializing and rates of delinquency. Criminology, 42(3), 519-550.

Osgood, D. W., Wilson, J. K., O'Malley, P. M., Bachman, J. G., \& Johnston, L. D. (1996). Routine activities and individual deviant behavior. American Sociological Review, 635-655.

Pratt, T. C., \& Cullen, F. T. (2000). The empirical status of Gottfredson and Hirschi's general theory of crime: A meta-analysis. Criminology, 38(3), 931-964.

Rawson, R. A., Maxwell, J., \& Rutkowski, B. (2007). OxyContin abuse: Who are the users? American Journal of Psychiatry. https://doi.org/10.1176/appi.ajp.2007.07091393

Shaw, C. R. (1931). The natural history of a delinquent career. Chicago: University of Chicago Press.

Shaw, Clifford R., and Henry D. McKay. 1942. Juvenile delinquency and urban areas. Chicago: University of Chicago Press.

Simpson, K. A., Kral, A. H., Goldshear, J. L., Wenger, L., Strike, C. S., \& Bluthenthal, R. N. (2020). Reasons for assisting with injection initiation: Results from a large survey of people who inject drugs in Los Angeles and San Francisco, California. Drug and Alcohol Dependence, 209, 107885.

Small, W., Fast, D., Krusi, A., Wood, E., \& Kerr, T. (2009). Social influences upon injection initiation among street-involved youth in Vancouver, Canada: a qualitative study. Substance Abuse Treatment, Prevention, and Policy, 4(1), 8.

Strike, C., Rotondi, M., Kolla, G., Roy, E., Rotondi, N. K., Rudzinski, K., Ballion, R., Guimond, T., Penn, R., Silver, R.B., Millson, M., Sirois, K., Altenberg, J., \& Hunt, J. (2014). Interrupting the social processes linked with initiation of injection drug use: results from a pilot study. Drug and Alcohol Dependence, 137, 48-54.

Sutherland, Edwin. 1947. Principles of criminology, Fourth Edition. Philadelphia: Lippincott.

Vazsonyi, A. T., Mikuška, J., \& Kelley, E. L. (2017). It's time: A meta-analysis on the self-controldeviance link. Journal of Criminal Justice, 48, 48-63.

Volkow, N. D., \& McLellan, A. T. (2016). Opioid abuse in chronic pain-misconceptions and mitigation strategies. New England Journal of Medicine, 374(13), 1253-1263.

Warr, M. (2002). Companions in crime: The social aspects of criminal conduct. Cambridge University Press.

Werb, D., R.N. Bluthenthal, G. Kolla, C. Strike, A.H., A Uuskula, D. Des Jarlais. (2018). Preventing injection drug use Initiation: State of the evidence and opportunities for the future. Journal of Urban 
Health, 9B5:91-98.

Werb, D., Buxton, J., Shoveller, J., Richardson, C., Rowell, G., and Wood, E. (2013). Interventions to prevent the initiation of injection drug use: A systematic review. Drug and Alcohol Dependence 133: 669676.

Wenger, L. D., Lopez, A. M., Kral, A. H., \& Bluthenthal, R. N. (2016). Moral ambivalence and the decision to initiate others into injection drug use: A qualitative study in two California cities. International Journal of Drug Policy, 37, 42-51.

Werb, D., Garfein, R., Kerr, T., Davidson, P., Roux, P., Jauffret-Roustide, M., ... \& Strathdee, S. A. (2016). A socio-structural approach to preventing injection drug use initiation: rationale for the PRIMER study. Harm Reduction Journal, 13(1), 25.

Witteveen, E., Van Ameijden, E. J., Prins, M., \& Schippers, G. M. (2007). Factors associated with the initiation of cocaine and heroin among problem drug users-Reflections on interventions. Substance Use \& Misuse, 42(6), 933-947. 
Table 1. Sample Characteristics $(n=370)$.

\begin{tabular}{lcccc}
\hline & $\mathbf{n}(\%)$ & Mean $( \pm$ SD) & Median & Range \\
\hline Age & & $33.48( \pm 8.36)$ & 31.71 & $18-59$ \\
Sex (Male) & $277(74.9 \%)$ & & \\
Latino/a (Yes) & $39(10.5 \%)$ & & \\
Race & & & \\
$\quad$ White & $308(83.2 \%)$ & & \\
$\quad$ Black & $10(2.7 \%)$ & & \\
$\quad$ Other & $52(14.1 \%)$ & & \\
Age Initiated Heroin Use & & $23.67( \pm 6.61)$ & \\
Yrs. Used Heroin & & $9.34( \pm 8.21)$ & 6.00 & $0-43$ \\
Detox from Heroin (Yes) & $325(87.8 \%)$ & & & \\
Self-Control & & & & \\
Initiated Other to Heroin (Yes) & $65(17.6 \%)$ & & & \\
Tried to Prevent Other (Yes) & $266(71.9 \%)$ & & & \\
\hline
\end{tabular}


Table 2. Logistic Regression Models Estimating the Adjusted Association of Background Characteristics and SelfControl with Initiating Others to Heroin and Trying to Prevent Others from Initiating Heroin Use $(n=370)$.

\begin{tabular}{|c|c|c|c|c|}
\hline & \multicolumn{2}{|c|}{ INITIATE OTHERS } & \multicolumn{2}{|c|}{ PREVENT OTHERS } \\
\hline & $\begin{array}{c}\text { Adj. OR } \\
(95 \% \text { CI }) \\
\end{array}$ & $\mathbf{z}(\mathbf{p}=)$ & $\begin{array}{l}\text { Adj. OR } \\
(95 \% \text { CI }) \\
\end{array}$ & $\mathbf{z}(\mathbf{p}=)$ \\
\hline Sex (Male) & $\begin{array}{c}1.00 \\
(0.53-1.91)\end{array}$ & $0.01(.998)$ & $\begin{array}{c}0.57 \\
(0.32-1.01)\end{array}$ & $-1.92(.055)$ \\
\hline Hispanic & $\begin{array}{c}0.72 \\
(0.24-2.20)\end{array}$ & $-0.57(.565)$ & $\begin{array}{c}0.50 \\
(0.21-1.21)\end{array}$ & $-1.53(.127)$ \\
\hline \multicolumn{5}{|l|}{ Race } \\
\hline Black & $\begin{array}{c}1.00 \\
(0.20-5.01)\end{array}$ & $-0.00(.998)$ & $\begin{array}{c}0.99 \\
(0.25-4.02)\end{array}$ & $-0.10(.992)$ \\
\hline Other & $\begin{array}{c}0.94 \\
(0.37-2.38)\end{array}$ & $-0.12(.903)$ & $\begin{array}{c}2.84 \\
(1.15-7.03)\end{array}$ & $2.26(.024)$ \\
\hline White [REF] & {$[1.00]$} & & {$[1.00]$} & \\
\hline Years of Heroin Use & $\begin{array}{c}0.98 \\
(0.95-1.02)\end{array}$ & $-0.97(.333)$ & $\begin{array}{c}1.01 \\
(0.98-1.04)\end{array}$ & $0.61(.542)$ \\
\hline Detox from Heroin & $\begin{array}{c}0.73 \\
(0.33-1.64)\end{array}$ & $-0.76(.447)$ & $\begin{array}{c}1.56 \\
(0.80-3.04)\end{array}$ & $1.31(.191)$ \\
\hline Self-Control & $\begin{array}{c}0.95 \\
(0.93-0.98)\end{array}$ & $-3.23(.001)$ & $\begin{array}{c}0.98 \\
(0.96-1.01)\end{array}$ & $-1.51(.132)$ \\
\hline
\end{tabular}


Table 3. Thinking about the most recent time you introduced someone to using heroin for the first time, what led you to do it $(\mathrm{n}=68)$ ?

\begin{tabular}{|c|c|c|}
\hline Reason & No & Yes \\
\hline \multicolumn{3}{|l|}{ Other-Focused Reasons } \\
\hline They asked me for the drug. & $12(17.7 \%)$ & $56(82.4 \%)$ \\
\hline I thought they would enjoy it. & $42(61.8 \%)$ & $26(38.2 \%)$ \\
\hline $\begin{array}{l}\text { They were withdrawing from another drug and I thought } \\
\text { heroin would help. }\end{array}$ & $51(75.0 \%)$ & $17(25.0 \%)$ \\
\hline Endorsed at least one altruistic reason. & $4(5.9 \%)$ & $64(94.1 \%)$ \\
\hline \multicolumn{3}{|l|}{ Self-Interested Reasons } \\
\hline I wanted someone to do it with. & $52(76.5 \%)$ & $16(23.5 \%)$ \\
\hline I wanted to do it with that person. & $57(83.8 \%)$ & $11(16.2 \%)$ \\
\hline I was dealing and trying to get new business. & $60(88.2 \%)$ & $8(11.8 \%)$ \\
\hline $\begin{array}{l}\text { My dealer gave me free drugs for bringing him or her new } \\
\text { business. }\end{array}$ & $63(92.7 \%)$ & $5(7.4 \%)$ \\
\hline $\begin{array}{l}\text { My dealer encouraged me to bring him or her new } \\
\text { business. }\end{array}$ & $64(94.1 \%)$ & $4(5.9 \%)$ \\
\hline Endorsed at least one selfish reason. & $44(64.7 \%)$ & $24(35.3 \%)^{\mathrm{a}}$ \\
\hline $\begin{array}{l}\text { Endorsed at least one altruistic reason and at least one } \\
\text { selfish reason. }\end{array}$ & $46(67.6 \%)$ & $22(32.3 \%)$ \\
\hline Reported Other reasons. & $63(92.7 \%)$ & $5(7.4 \%)^{\mathrm{b}}$ \\
\hline
\end{tabular}

a Includes 1 person who said they initiated the person to heroin because that person had molested them when younger.

b Two "other" reasons, "he molested me when I was younger" and "more people using around you, better supports you" reflect more selfish reasons and one "other" reason, "they had problems" reflect more altruistic reasons. These were coded yes for overall endorsement rates. 
Table 4. Reasons for Initiating Heroin Use $(\mathrm{n}=370)$.

\begin{tabular}{|c|c|c|}
\hline Reason & No & Yes \\
\hline \multicolumn{3}{|l|}{ Selfish Supplier-Motivated Reasons } \\
\hline Someone pressured me into using it. & $326(88.1 \%)$ & $44(11.9 \%)$ \\
\hline Someone tricked me into using it. & $345(93.5 \%)$ & $24(6.5 \%)$ \\
\hline $\begin{array}{l}\text { I thought it would make someone happy if I used it with } \\
\text { them. }\end{array}$ & $348(94.1 \%)$ & $22(6.0 \%)$ \\
\hline Endorsed one or more selfish supplier-motivated reasons. & $299(80.8 \%)$ & $71(19.2 \%)$ \\
\hline \multicolumn{3}{|l|}{ Unselfish Supplier-Motivated Reasons } \\
\hline Someone offered and I accepted. & $175(47.3 \%)$ & $195(52.7 \%)$ \\
\hline In withdrawal and someone suggested heroin. & $223(60.3 \%)$ & $147(39.7 \%)$ \\
\hline Endorsed one or both unselfish supplier-motivated reasons. & $126(34.1 \%)$ & $244(65.9 \%)$ \\
\hline \multicolumn{3}{|l|}{ Neutral Self-Motivated Reasons } \\
\hline It was cheaper for me to buy than pain pills. & $147(39.7 \%)$ & $223(60.3 \%)$ \\
\hline I just wanted to try it. & $150(40, .5 \%)$ & $220(59.5 \%)$ \\
\hline $\begin{array}{l}\text { I was withdrawing from some other drug and I couldn't get } \\
\text { it on the street. }\end{array}$ & $223(60.3 \%)$ & $147(39.7 \%)$ \\
\hline $\begin{array}{l}\text { I was already drunk or high on some other drug and used it } \\
\text { without thinking about it too much. }\end{array}$ & $318(86.0 \%)$ & $52(14.1 \%)$ \\
\hline Endorsed one or more neutral reasons. & $30(8.1 \%)$ & $340(91.9 \%)$ \\
\hline Other Reasons & $313(84.6 \%)$ & $57(15.4 \%)^{\mathrm{a}}$ \\
\hline
\end{tabular}

a Five persons said they initiated heroin use because their male partners were using, 3 said they were around others who were using heroin, 2 said they were forced to use heroin (one said "held down and injected"), 8 said they were having psychological problems, 5 said to come down from crack or cocaine, 5 said because of pain, 4 said to cope with a loss, and 6 said they were dealing. Nineteen persons identified other reasons that could not be readily categorized. 


\section{APPENDIX A: SELF-CONTROL INDEX}

1. I often act on the spur of the moment.

2. frequently try to avoid things I know will be difficult.

3. I like to test myself every now and then by doing something a little risky.

4. If I had a choice, I would almost always rather do something physical than something mental.

5. I try to look out for myself first, even if it means making things difficult for other people.

6 . I lose my temper pretty easily.

7. I don't devote much thought and effort to preparing for the future.

8. When things get complicated, I tend to quit or withdraw.

9. Sometimes I will take a risk just for the fun of it.

10. I almost always feel better when I am on the move than when I am sitting and thinking.

11. I'm not very sympathetic to other people when they are having problems.

12. Often, when I'm angry at people, I feel more like hurting them than talking to them about why I'm angry.

13. I often do whatever brings me pleasure here and now, even at the cost of future goals.

14. The things in life that are the easiest to do bring me the most pleasure.

15. I sometimes find it exciting to do things for which I might get in trouble.

16. I like to get out and do things more than I like to read or contemplate ideas.

17. If things I do upset other people, it's their problem, not mine.

18. When I am really angry, other people better stay away from me.

19. I am more concerned with what happens to me in the short run than in the long run.

20. I dislike really hard tasks that stretch my abilities to the limit.

21. Excitement and adventure are more important to me than security.

22. I seem to have more energy and greater need for activity than most other people my age.

23. I will try to get the things I want even when I know it's causing problems for other people.

24. When I have a serious disagreement with someone, it's usually hard for me to talk about it without getting upset.

a Grasmick et al. (1993). Items were coded 1, strongly agree, to 5, strongly disagree. Higher scores represent higher self-control. Internal consistency reliability in this sample was .825 . 